\title{
APOKRYFY NOWEGO TESTAMENTU JAKO INSPIRACJA DLA SZTUKI CHRZEŚCIJAŃSKIEJ: PRZYPADEK IKONOGRAFII PRÓBY GORZKIEJ WODY W ETIOPSKICH ILUMINACJACH ${ }^{1}$
}

\section{SZTUKA CHRZEŚCIJAŃSKIEJ ETIOPII}

Sztuka chrześcijańskiej Etiopii stanowi interesujący przykład krzyżowania się wpływów kulturowych. U jej podstaw legło spotkanie chrześcijaństwa w jego orientalnej miafizyckiej odmianie z afrykańską kulturą Wyżyny Abisyńskiej². Tradycje ekspresji artystycznej obu tych kultur doprowadziły do powstania charakterystycznej i unikalnej ikonografii, która rozwijając się przez wieki przyjmowała także inspiracje z innych kręgów kulturowych. W rozmaitych okresach i w różnym natężeniu w sztuce etiopskiej można odnaleźć wpływy indyjskie, ormiańskie, arabskie, portugalskie i inne.

Na przełomie XIX i XX wieku w Cesarstwie Etiopskim rozpoczęła się obejmująca niemal wszystkie dziedziny życia modernizacja i westernizacja. Objęła ona także wytwarzanie sztuki i jej kontekst społeczny. Rynek sztuki, pozycja społeczna artystów, podejmowane tematy zbliżyły się do swoich europejskich odpowiedników.

W tym tekście przedmiotem zainteresowania będzie jednak wyłącznie sztuka chrześcijańska okresu przednowoczesnego, którą cechowały swoiste uwarunkowania. Wskazać można następujące czynniki warunkujące miejsce sztuki figuratywnej w kulturze chrześcijańskiej przednowoczesnej Etiopii:

1) Sztuka była podporządkowana teologii $w$ tym sensie, że występujące w niej motywy były przejmowane z piśmiennictwa religijnego, przede wszystkim z Biblii. W przypadku malarstwa ściennego stanowiącego dekorację kościołów, była również ściśle związana z liturgią. Zgodnie ze zwyczajem praktykowa-

\footnotetext{
* Dr Marcin KonRad KraWczuK - Katedra Języków i Kultur Afryki, Wydział Orientalistyczny, Uniwersytet Warszawski, e-mail:mkrawczuk@uw.edu.pl.

${ }^{1}$ Z przyczyn prawnych nie było możliwe zaopatrzenie niniejszego tekstu w ilustracje. Zamiast tego podaję sygnatury zdjęć dostępnych na stronie www Mäzgäbä Ś``əlat (dalej MS, http://128.100.218.174:8080/login.jsp login i hasło „student”).

2 A. Pawłowska, Selected motifs of Ethiopian iconography, Series Byzantina 2009, vol. 7, s. 83.
} 
nym do dzisiaj na terenach wiejskich, wierni wchodzili do kościoła jedynie w celu przyjęcia sakramentów, przez większość część mszy przebywając na zewnątrz kościoła. Malowidła były rozmieszczane w kościele zgodnie z dość ściśle określonym symbolicznym porządkiem i funkcjonowały jako tło dla czynności liturgicznych.

2) Artyści w niewielkim stopniu wykazywali się oryginalnością, a raczej kopiowali w miarę swoich możliwości technicznych pierwowzory przejęte skądinąd. Niekiedy daje się ustalić, dokładnie które ryciny z książek przywiezionych do Etiopii przez katolickich misjonarzy były kopiowane. W przypadku dawnej sztuki (o czym będzie jeszcze mowa) takie podejście sprawia, że w Etiopii zachowały się niektóre motywy, które wyszły z użycia w sztuce chrześcijańskiej innych obszarów bądź są słabo zaświadczone.

3) Wbrew częstym wyobrażeniom, nie podejmowano raczej prób indygenizacji motywów zapożyczonych z innych kultur. Dopiero od XVII wieku daje się zauważyć powolne wplatanie w ikonografię religijną elementów etiopskiej codzienności np. w scenach ucieczki Świętej Rodziny do Egiptu Maryja niesie dziecko na plecach, jak powszechnie robią to kobiety w całej Afryce.

4) Ikonografia jest w pełni zrozumiała tylko w kontekście tekstów. W tym sensie sztuka etiopska jest komplementarna wobec obszernej i różnorodnej chrześcijańskiej literatury Etiopii spisywanej przez wieki w języku gəəəz.

5) Sztuka powstawała w klasztorach i była tworzona przez mnichów. Działalność artystyczna była traktowana jako rzemiosło, to zaś nie cieszyło się poważaniem w kulturze etiopskiej (rozumianej jako kultura grup etnicznych wyznających w większości ortodoksyjne chrześcijaństwo a więc Amharów i Tigrajczyków), opartej na etosie rolniczym ${ }^{3}$. Sztuka była w związku z tym w ogromnej większości anonimowa.

6) Jak się wydaje, ikonografia nie była przedmiotem sporów natury teologicznej. Nie są udokumentowane żadne próby cenzurowania czy potępiania jakichś przedstawień przez hierarchię kościelną czy władzę. Są natomiast znane stosunkowo nieliczne przykłady promowania pewnych motywów. Tak działo się na przykład za panowania cesarza Zär’a Ya‘əqoba (panowanie w latach 1434-1468), który nakazał sporządzać wizerunki maryjne ${ }^{4}$.

Ponieważ w niniejszym tekście skupimy się przede wszystkim na iluminacjach, warto rozpocząć od przeglądu najważniejszych informacji dotyczących produkcji i iluminowania ksiąg w Etiopii.

Przypuszcza się, że technika produkcji pergaminu pojawiła się w Etiopii równocześnie z przyjęciem chrześcijaństwa przez władców istniejącego w starożytności na terenie obecnej Etiopii i Erytrei państwa Aksum. Miało to miejsce w pierwszej połowie

${ }^{3} \mathrm{Na}$ temat pozycji społecznej artystów zob. M. Heldman, Creating religious art: the status of artisans in highland Christian Ethiopia, Aethiopica 1998, vol. 1, s. 131-147.

${ }^{4} \mathrm{Na}$ ten temat zob. S. Kaplan, Seeing is believing: the power of visual culture in the religious world of aşe Zär'a Ya'eqob of Ethiopia (1434-1468), Journal of Religion in Africa 2002, vol. 32, no. 4 , s. 403-421. 
IV wieku. Pojawienie się nowej religii pociągnęło za sobą konieczność thumaczenia i utrwalenia na piśmie dużej ilości tekstów, w szczególności Biblii i tekstów liturgicznych 5 .

Za najstarszy rękopis etiopski uznawana jest powszechnie tzw. ewangelia Garimy, która według najnowszych ustaleń powstała między V a VII wiekiem ${ }^{6}$. Większość spośród zachowanych wczesnych rękopisów etiopskich stanowią ewangelie. Bardziej zróżnicowane pod względem treści i liczniejsze są dopiero rękopisy powstające od wieku XVI wieku. Pomimo pojawienia się w Etiopii druku pod koniec XIX wieku, kultura produkcji pergaminowych rękopisów nie wyginęła do dzisiaj, choć oczywiście uległa znacznemu ograniczeniu i dużym przeobrażeniom?

Wiele spośród etiopskich rękopisów zawiera oprócz tekstu także iluminacje. Bogato ilustrowane są w szczególności ewangelie, żywoty świętych oraz utwory o tematyce maryjnej. Technika sporządzania iluminacji zależała od dostępnych lokalnie materiałów, natomiast pierwowzory ikonograficzne były przeważnie przejmowane z kultur artystycznych innych chrześcijańskich obszarów ${ }^{8}$.

Historycy sztuki wydzielają trzy okresy w dziejach etiopskiej sztuki iluminacji. Najstarszy okres obejmuje wieki XIII-XV. Iluminacje z tego okresu pochodzą niemal wyłącznie z rękopisów ewangelii. Zajmują zwykle całe folio (w formie frontyspisu) i umieszczane są na początku rękopisu, przed tekstem. Standardowy cyk1 iluminacji rozpoczyna się od bogato dekorowanych tablic kanonicznych, po nich wyobrażone są sylwetki ewangelistów oraz wybrane sceny z życia Jezusa ułożone w kolejności chronologicznej. Sposób przedstawienia jest uproszczony i hieratyczny. Iluminacjom towarzyszą podpisy w języku gə‘əz identyfikujące poszczególne sceny.

Drugi okres obejmuje w przybliżeniu lata panowania tzw. dynastii gonderskiej ${ }^{9}$ czyli wieki XVII-XVIII. Poszerzono wówczas znacznie zakres motywów występujących w sztuce. Choć zachowała ona ściśle religijny charakter, zaczęto włączać w ikonografię elementy etiopskiej codzienności. Warsztat artystyczny wyraźnie się rozwinął, dzięki czemu iluminacje cechuje dużo większy realizm i ekspresja. Zmienił się także układ rękopisu. Iluminacje z tego okresu są raczej wplatane w tekst niż grupowane razem. Nie mają ponadto zwykle podpisów. Najpóźniejszy okres sztuki iluminacji trwający od połowy XVIII wieku cechuje daleko idąca sekularyzacja malarstwa i stopniowe zrywanie więzi pomiędzy sztuką a kościołem ${ }^{10}$.

5 A. Bausi, Writing, copying, translating: Ethiopia as manuscript culture, w: Manuscript cultures: mapping the field, ed. by Jörg B. Quenzer, Dmitry Bondarev, and Jan-Ulrich Sobisch, Berlin-Boston 2014, s. 37-77.

${ }^{6}$ M. Krawczuk, Ewangeliarz abba Garima - najstarszy znany rękopis etiopski, „Iluminacje” 2013, nr 1, s. 21-23.

${ }^{7} \mathrm{Na}$ temat produkcji pergaminowych rękopisów we współczesnej Etiopii zob. M. Krzyżanowska, Contemporary scribes of eastern Tigray (Ethiopia), Rocznik Orientalistyczny 2015, vol. 68, no. 2, s. 73-101.

${ }^{8}$ E. Balicka-Witakowska, O ksiażce etiopskiej, Studia o Książce 1975, T. 5, s. 81-84.

${ }^{9}$ Nazywanej tak od miasta Gonder, w którym znajdowała się siedziba cesarzy.

${ }^{10}$ O. Jäger, L. Deininger-Englhart, Some notes on illumination of manuscripts in Ethiopia, Rassegna di Studi Etiopici 1961, vol. 17, s. 45-60. 


\section{PRÓBA GORZKIEJ WODY I JEJ IKONOGRAFIA W OKRESIE WCZESNOCHRZEŚCIJAŃSKIM}

Próba gorzkiej wody jest zwyczajem pochodzącym ze Starego Testamentu (Lb 5, 11-31). Gdy mężczyzna podejrzewał swoją żonę o niewierność, a nie miał na to dowodu ani świadka, żona miała być przyprowadzona przed oblicze kapłana. Po złożeniu przez kapłana ofiary z mąki podawano kobiecie do wypicia specjalnie przygotowany napój. Jeżeli podejrzenie okazałoby się słuszne, kobieta miałaby doznać ogromnych boleści. W przeciwnym razie wyszłaby z próby bez szwanku.

W Starym Testamencie nie ma (ewentualnie z wyjątkiem Ps $109,18^{11}$ ) żadnej innej wzmianki o tej praktyce ani żadnego wypadku zastosowania tego prawa w praktyce, co stawia pod znakiem zapytania jego faktyczne obowiązywanie ${ }^{12}$. Mimo to przepisy te znalazły swoje rozwinięcie w Misznie, w traktacie Sôtā. O zwyczaju wspominają także starożytni żydowscy historycy: Filon z Aleksandrii i Józef Flawiusz (Antiquitates Iudaicae ks. 3, rozdział 11).

Już w czasach chrześcijańskich motyw próby został podjęty w Protoewangelii Jakuba (ProtJak 15-16) ${ }^{13}$. Pochodzący z II wieku apokryf gatunkowo przynależy do popularnego rodzaju tekstów, jakim są ewangelie dzieciństwa. Charakterystyczne dla tego utworu jest jego szczególne skupienie na postaci Maryi, której poświęcone jest około $2 / 3$ dzieła $^{14}$.

Okoliczności próby Protoewangelia Jakuba wyjaśnia następująco. Maryja zostaje przez swoich rodziców ofiarowana do Świątyni. Osiągnąwszy wiek dwunastu lat, zostaje dana w opiekę jako żona Józefowi. Pod nieobecność Józefa anioł zwiastuje Maryi dobrą nowinę. Gdy Maryja jest szóstym miesiącu ciąży, Józef powraca i rozpacza widząc ją brzemienną. Kapłan Annasz dowiedziawszy się o tym stanie rzeczy, zaczyna czynić obojgu wyrzuty. Arcykapłan, powiadomiony o fakcie, zmusza oboje do poddania się próbie gorzkiej wody. Próba oczywiście nie wykazuje winy i oskarżenie zostaje oddalone ${ }^{15}$.

Motyw próby, jakiej została poddana Maryja, można interpretować na co najmniej dwa sposoby, zresztą niesprzeczne ze sobą, a wręcz uzupełniające się wzajemnie. Pierwsza interpretacja w sposób dość prosty wynika z logiki narracji. Opis próby znajduje się tuż po opisie Zwiastowania (ProtJak 11-12), a przed Narodzeniem (ProtJak 19-20), podczas którego Świętej Rodzinie towarzyszy nieobec-

11 „Niech się odzieje przekleństwem jak szatą; niech ono przeniknie jak woda do jego wnętrzności”.

12 [G. B. Gray], Jealousy, Ordeal of, w: Encyclopedia Biblica. Vol. 2, ed. by T. K. Cheyne, J. Sutherland Black, London 1903, kol. 2341-2343.

${ }_{13}$ M. Geerard (red.), Clavis apocryphorum Novi Testamenti, Turnhout 1992, s. 25-29.

${ }_{14}^{14}$ H. Langkammer, Apokryfy Nowego Testamentu, Katowice 1989, s. 30-33.

${ }_{15}$ Por. Apokryfy Nowego Testamentu. T. 1, Ewangelie apokryficzne, pod red. M. Starowieyskiego, Lublin 1980, s. 197-198. 
na w ewangeliach kanonicznych postać akuszerki Salome. Wszystkie trzy sceny zdają się mieć jednakową funkcję, zaświadczają mianowicie o dziewictwie Maryi zarówno ante jak i post partum.

Druga, nieco bardziej nieoczywista interpretacja, opiera się na założeniu, iż pierwotnymi adresatami Protoewangelii były osoby zaznajomione z tradycją żydowską. Dla tych odbiorców istotna była zawarta w tekście symbolika, akcentująca szczególny związek Maryi ze Świątynią. W Protoewangelii Maryja zostaje jako dziecko ofiarowana w Świątyni, zaś poddanie jej próbie sprawiło, iż mogła ona, pomimo bycia kobietą, złożyć ofiarę w Świątyni ${ }^{16}$.

W sztuce chrześcijańskiej przedstawienia próby gorzkiej wody należą do wielkiej rzadkości ${ }^{17}$. Jednym z najsłynniejszych przedstawień jest jeden z paneli z kości słoniowej na tronie Maksymiana, biskupa Rawenny, pochodzącym z VI wieku. Z podobnego okresu pochodzi plakietka z kości słoniowej z Syrii przechowywana w Luwrze. Na obu zabytkach obok kanonicznej sceny Zwiastowania, występują sceny apokryficzne: próba gorzkiej wody i narodziny Jezusa, którym towarzyszy akuszerka Salome ${ }^{18}$. Jako próba gorzkiej wody może być interpretowana scena znajdująca się na dyptyku z kości słoniowej przechowywanym w katedrze w Mediolanie $^{19}$. Do zabytków zawierających to rzadkie przedstawienie należą także dwa kościane dyptyki (oryginalnie służące jako oprawa kodeksu), bardzo bliskie stylistycznie - znajdują się obecnie: jeden w Bibliotece Narodowej w Paryżu (ewangelia St. Lupicin), drugi w Mantendaranie w Erewaniu. Nieco późniejsze od powyższych, bo pochodzące z VIII wieku, jest przedstawienie próby gorzkiej wody na jednym z fresków w kościele Santa Maria Foris Portas w Castelseprio (Lombardia) ${ }^{20}$.

We wszystkich powyższych wypadkach przedstawienie próby gorzkiej wody nie jest autonomicznym dziełem, ale stanowi każdorazowo element szerszego cyklu ikonograficznego obejmującego wiele scen z życia Maryi i Jezusa. Warto także zauważyć, że chociaż normą w sztuce wczesnochrześcijańskiej było przejmowanie w sztuce dekoracyjnej czy malarstwie ściennym motywów z iluminacji rękopi-

${ }^{16}$ M. Nutzman, Mary in the Protevangelium of James: a Jewish woman in the Temple?, Greek, Roman, and Byzantine Studies 2013, vol. 53, no. 3, s. 563.

17 Obszerne informacje na temat motywu próby w sztuce wczesnochrześcijańskiej wraz z przeglądem najważniejszych zabytków zawiera: E. Jastrzębowska, Bild und Wort : das Marienleben und die Kindheit Jesu in der christlichen Kunst vom 4. bis 8. Jh. und ihre apokryphen Quellen, Warszawa 1992, s. 94-96, 144-146, 165, 217, 231-240.

18 R. M. Jensen, The apocryphal Mary in early Christian art, w: The Oxford handbook of early Christian apocrypha, ed. by Andrew Gregory, Christopher M. Tuckett, Tobias Nicklas, Joseph Verheyden, Oxford 2016, s. 293.

19 Z. Frantová, Hereze a lojalita: slonovinový Diptych z pěti částí z pokladu katedrály v Miláně, Brno 2014, s. 176-177. Inne możliwe interpretacje sceny to ofiarowanie Maryi w Świątyni bądź zwiastowanie.

20 A. Grabar, Les fresques de Castelseprio, Gazette des Beaux-Arts 1950, no 37, s. 107-114. 
sów ${ }^{21}$, nie znamy w istocie żadnej wczesnochrześcijańskiej iluminacji zawierającej przedstawienie próby.

\section{APOKRYFY MARYJNE W ETIOPII I INNE TEKSTY WSPOMINAJĄCE O PRÓBIE}

Jak wspomniano powyżej, etiopska sztuka pozostawała w ścisłym związku z tekstami. Dlatego też przed analizą etiopskich przedstawień próby gorzkiej wody trzeba poświęcić kilka słów obecności tego motywu w piśmiennictwie. Literatura etiopska należy do największych objętościowo literatur chrześcijańskiego Wschodu. Była spisywana w języku gə‘əz, a jej początki sięgają IV wieku, kiedy to dokonano na ten język tłumaczenia Septuaginty. Za okres jej rozkwitu przyjąć można wieki od XIV do XVII, kiedy to powstało (bądź zostało przetłumaczonych) najwięcej tekstów. Pod koniec XIX wieku głównym językiem pisanym w Cesarstwie Etiopskim stał się amharski, gə‘əz pozostał natomiast do dzisiaj językiem liturgicznym.

Wśród zachowanych dzieł piśmiennictwa etiopskiego znajduje się wiele apokryfów zarówno Starego jak i Nowego Testamentu, w większości tłumaczonych z greki bądź z arabskiego, ale są też oryginalne kompozycje. Do pewnego stopnia daje się zauważyć prawidłowość, że apokryfy Starego Testamentu były tłumaczone $\mathrm{z}$ większą intensywnością $\mathrm{w}$ dawniejszym okresie literatury etiopskiej tj. do około VII wieku. Wtedy przełożono na gə‘əz m. in. Księgę Henocha czy Księgę Jubileuszy, ogromnie istotne apokryfy żydowskie okresu okołotestamentalnego. Były one tłumaczone w całości. Natomiast apokryfy Nowego Testamentu są w dużej liczbie zaświadczone dopiero od XIV-XV wieku. Często są one tłumaczone fragmentarycznie bądź parafrazowane ${ }^{22}$.

Protoewangelia Jakuba funkcjonuje w Etiopii pod nazwą Maṣhafa lədatā laMāryām („Księga narodzin Maryi”) i jest stosunkowo wiernym tłumaczeniem, choć nie jest w pełni przesądzone, z jakiego języka. W literaturze przedmiotu nie zaproponowano także żadnego dobrze uzasadnianego datowania powstania etiopskiej wersji ${ }^{23}$. Narracja na temat próby gorzkiej wody (określanej jako mayä zäläfa „woda potępienia”) nie odbiega w istotnych szczegółach od pierwotnej wersji ${ }^{24}$. Motyw próby znajdujemy w również innych funkcjonujących w Etiopii

${ }^{21}$ K. Weitzmann (red.), Age of spirituality. Late Antique and Early Christian art, Third to Seventh Century, New York 1979, s. 450.

${ }_{22}$ P. Piovanelli, Les aventures des apocryphes en Éthiopie, Apocrypha 1994, no 4, s. 197-224.

${ }^{23}$ Pobieżny przegląd katalogów rękopisów etiopskich pokazuje, że wszystkie rękopisy zawierające ten tekst są dużo późniejsze niż omawiane w artykule ewangelie zawierające iluminacje z próbą gorzkiej wody.

${ }^{24}$ M. Chaine, Apocrypha de B. Maria Virgine, Romae [etc.] 1909 (Corpus scriptorum christianorum orientalium. Scirptores aethiopici; t. 7), s. 11 (tekst etiopski). 
ewangeliach apokryficznych, wydaje się jednak, iż są one pod tym względem zależne od Maṣhafa ladatā laMāryāmm².

Można odnieść wrażenie, że motyw próby nie był szczególnie eksponowany w etiopskich tekstach maryjnych bądź wręcz, że pojawiał się w nich jedynie wyjątkowo ${ }^{26}$. Należy jednak sądzić, że historia ta była znana przynajmniej w kręgach osób o zaawansowanej wiedzy religijnej. Próba wspominana jest na przykład w tzw. andəmta czyli tradycyjnych komentarzach do świętych tekstów ${ }^{27}$.

\section{WYBRANE PRZEDSTAWIENIA PRÓBY GORZKIEJ WODY W ETIOPSKICH ILUMINACJACH}

Przedstawienia Maryi należą niewątpliwie do najczęściej występujących motywów sztuki etiopskiej. Ikonografia maryjna jest bogata i różnorodna, swoje źródło czerpie zarówno z Ewangelii kanonicznych, jak i apokryfów ${ }^{28}$.

Najstarsze etiopskie przedstawienie próby gorzkiej wody znajduje się w ewangelii, która należała do mnicha 'Iyäsus Mo'a, przeora klasztoru Däbrä Ḥayq 'Gsțifanos. Jest to zarazem najstarszy rękopis etiopski, którego datowanie, dzięki zawartemu kolofonowi jest pewne i dokładne - pochodzi on z 1280 bądź $1281 \mathrm{roku}^{29}$. Na f. $17 \mathrm{v}$ widzimy w górnej części scenę Zwiastowania, u dołu zaś scenę próby gorzkiej wody. Jednoznaczna identyfikacja obu scen możliwa jest dzięki podpisom. Podpis pod dolną sceną brzmi: habä 'astäya Yosef läMaryam mayä zäläfa tj. ,jak [dosł. gdzie] Józef dał Maryi do picia wodę potępienia". Maryja stoi w centrum pięcioosobowej grupy. Po jej prawej ręce stoi Józef wręczający jej kielich. Po lewej zaś widoczna jest postać stojąca $\mathrm{w}$ pozie oranta $\mathrm{z}$ rękoma wzniesionymi ku niebu. Zapewne

25 Przykładem może być apokryf określany jako Tä’ammərä 'Iyäsus („Cuda Jezusa”), por. W. Witakowski, The Miracles of Jesus: an Ethiopian apocryphal gospel, Apocrypha 1995, no 6, s. 279-298.

26 Jako świadectwo stosunkowo marginalnej roli próby w mariologii etiopskiej wskazać można również fakt, iż wśród rozlicznych świąt maryjnych Kościoła etiopskiego nie ma wspomnienia próby, choć w kalendarzu jest szereg świąt o ewidentnie apokryficznej genezie (jak święto Ofiarowania Maryi w Świątyni czy Zaśnięcia.

27 Por. np. Waddäse Maryam qaddus Efrem yädärräsäw: käqädmo abbatočč siwärd siwarräd yämätțaw nəbabunna tərgwame [Pochwała Marii napisana przez świętego Efrema: tłumaczenie i objaśnienie przekazane w tradycji przez dawnych ojców], Addis Abäba 1983 [=1990/1991], s. 161.

28 Bogato ilustrowany przegląd etiopskiej ikonografii maryjnej daje: J. Mercier, Vierges d'Éthiopie, Montpellier 2004.

29 Rękopis został zmikrofilmowany i dokładnie skatalogowany, zob. Getatchew Haile, A catalogue of Ethiopian manuscripts microfilmed for the Ethiopian Manuscript Microfilm Library, Addis Ababa, and for the Monastic Manuscript Microfilm Library, Collegeville, vol. 5, Collegeville 1981, s. $293-$ 301. Sygnatura w MS: MG-2000.004:004. 
należy ją interpretować jako arcykapłana. Mniej oczywista jest interpretacja obecności dwóch dodatkowych postaci po skrajnej lewej i prawej stronie, których nie znajdujemy w żadnym z przedstawień pochodzących spoza Etiopii. Być może są to przypadkowe osoby zgromadzone w Świątyni.

Podobny układ scen (ze Zwiastowaniem u góry i próbą u dołu) widzimy na f. $8 \mathrm{v}$ w iluminacji z ewangelii z klasztoru Boru Śəllase ${ }^{30}$. Z braku innych danych $\mathrm{W}$ rękopisie iluminacja musi być datowana jedynie na podstawie cech stylistycznych na XIV-XV wiek ${ }^{31}$. Podpis do iluminacji głosi: zäkämä ’ästäyəwwo mayä zäläfa tj. ,jak dali mu [!] do picia wodę potępienia”. Należy stąd wnosić, że stojąca po lewej ręce Maryi postać trzymająca kielich to Józef. Tym samym jest to jedyna spośród iluminacji, która ściśle oddaje sytuację opisaną w Protoewangelii Jakuba, iż to Józef jako pierwszy musiał poddać się próbie. Postać po prawej ręce Maryi przedstawia zatem zapewne arcykapłana.

Z kolei iluminacja pochodząca $\mathrm{z}$ ewangelii przechowywanej w klasztorze 'Ahaya Fağğ Däbrä Qwesqwam datowanej na XIV wiek zawiera dwa bardzo ważne szczegóły nieobecne w omawianych powyżej iluminacjach ${ }^{32}$. Tuż przy Maryi, u jej stóp, widoczny jest niewielki obiekt przypominający kształtem piramidę. $Z$ uwagi na kontekst prawdopodobna jest możliwość, iż jest to źródło czy też studnia, z której, jak opisuje to Księga Liczb, pobierano wodę do przeprowadzenia próby. Jeszcze istotniejszy jest łuk zwieńczający całą scenę oraz wisząca nad zgromadzonymi lampa. Lampa pojawia się w wielu wczesnych etiopskich iluminacjach, a jej symbolika jest ważna i złożona. Według zaproponowanej niedawno interpretacji, lampa ta stanowi reminiscencję lampy, która wisiała w Jerozolimie przy grobie Chrystusa, symbolizując zarazem zmartwychwstanie jak i obecność Boga. Jednocześnie grób Chrystusa stanowi chrześcijański ekwiwalent sanktuarium żydowskiej Świątyni ${ }^{33}$.

Z kolei tzw. ewangelia księżniczki Zir Ganäla pochodząca z 1401 roku zdaje się w sposób całościowy łączyć wszystkie elementy składające się na etiopską ikonografię sceny ${ }^{34}$. Widnieje na niej postać Maryi, Józef wręczający jej kielich, postać, którą można interpretować jako oranta, lampa, źródło oraz inne niepodpisane osoby. Postaci mają oczy zwrócone ku niebu, co jest charakterystyczne dla wszystkich iluminacji z tego rękopisu.

Wszystkie omówione powyżej przedstawienia należą do starszego okresu malarstwa etiopskiego. Pod względem ikonograficznym wyróżnia się ewangelia z Boru Śəllase, gdzie cała scena rozgrywa się w gronie trzech osób (czyli Maryi,

30 MS: SC-018.008:005.

31 E. Balicka-Witakowska, La Crucifixion sans Crucifié dans l'art éthiopien : recherches sur la survie de l'iconographie chrétienne de l'antiquité tardive, Warszawa 1997, s. 128-129.

32 MS: DS-1973.007:003.

33 J. Gnisci, Picturing the liturgy: notes on the iconography of the Holy Women at the Tomb in Fourteenth-and early Fifteenth-Century Ethiopian manuscript illumination, Bulletin of the School of Oriental and African Studies 2015, vol. 78, iss. 3, s. 566, 574.

34 MS: EBW-001.004:004. 
Józefa i prawdopodobnie arcykapłana), a więc dokładnie jak na dyptyku z Matendaranu. Na pozostałych przedstawieniach w scenie występuje pięć lub sześć osób. Takie przedstawienie nie ma pierwowzoru w sztuce chrześcijańskiej, można zatem dopatrywać się tu etiopskiej innowacji, lub (co bardziej prawdopodobne) oparciu się Etiopczyków na pierwowzorze, który nie zachował się do naszych czasów ${ }^{35}$.

Bardzo nieliczne przedstawienia próby gorzkiej wody w iluminacjach z okresu gonderskiego nie pochodzą z rękopisów ewangelii i, choć niewątpliwie o wiele bardziej udane artystycznie, są dużo uboższe w treści symboliczne od swoich starszych odpowiedników. Osiemnastowieczna iluminacja pochodząca z jednego z klasztorów w miejscowości Lalibela ${ }^{36}$ stanowi tutaj dobry przykład. Ilustracja pochodzi z rękopisu apokryfu określanego tytułem Nägärä Maryam („Opowieść o Maryi"), którego głównym tematem jest pobyt Świętej Rodziny w Egipcie i towarzyszące mu cuda ${ }^{37}$. Zgodnie z typową dla epoki konwencją, zarówno Maryja jak postaci męskie ubrane są w szaty zdradzające inspirację indyjską. Brak podpisów uniemożliwia pewną identyfikację postaci męskich, charakterystyczny jest również brak jakiegokolwiek nawiązania do miejsca przeprowadzenia próby - scena wydaje się rozgrywać wręcz na wolnym powietrzu. W podobnej konwencji utrzymana jest iluminacja $\mathrm{z}$ również osiemnastowiecznego modlitewnika ${ }^{38} \mathrm{z}$ tą różnicą, iż $\mathrm{w}$ tle znajduje się bliżej nieokreślony budynek. W zasadzie jedynym kryterium identyfikacji obu scen jako próby gorzkiej wody jest fakt trzymania przez Maryję kielicha.

\section{PRÓBA INTERPRETACJI PRZEDSTAWIEŃ PRÓBY GORZKIEJ WODY W KONTEKŚCIE ETIOPSKIM}

Kult maryjny odgrywa wielką rolę w ortodoksyjnym chrześcijaństwie etiopskim. Jego zasadniczy kształt nie odbiega rzecz jasna od kultu maryjnego w kościołach katolickim czy prawosławnym, ma on jednak swoją wyraźną lokalną specyfikę ${ }^{39}$. Wyjątkowa pozycja Maryi wynika z faktu, iż jest matką Zbawiciela, którego

${ }^{35}$ Zjawisko przetrwania w Etiopii wczesnochrześcijańskiego tematu ikonograficznego zaginionego gdzie indziej sygnalizowane $\mathrm{m}$. in $\mathrm{w}$ C. Lepage, Reconstitution d'un cycle protobyzantin à partir des miniatures de deux manuscrits éthiopiens du XIVe siècle, „Cahiers Archéologiques” 1987, vol. 35, s. 159-196 ; G. Fiaccadori, Bisanzio e il regno di Aksum: sul manoscritto Martini Etiop. 5 della Biblioteca Forteguerriana di Pistoia, Bollettino del Museo Bodoniano di Parma 1993, T. 7, s. 161-199.

${ }^{36}$ MS: MG-1993.035:013.

37 Wydaje się, że funkcjonowało wiele alternatywnych wersji tekstu, który nie posiada niestety wydania krytycznego. Tłumaczenie jednej z wersji znaleźć można w: E. A. Wallis Budge, Legends of Our Lady Mary the Perpetual Virgin and her mother Hannâ, London 1922, s. 202-235.

38 MS: MG-2000.041:015.

${ }^{39}$ Szerzej na ten temat zob. M. Krawczuk, Kult maryjny w Etiopskim Kościele Ortodoksyjnym, Afryka 2015, T. 41, s. 67-80. 
urodziła zachowując dziewictwo. Interesujące i, jak się wydaje, szczególnie charakterystyczne dla Etiopii, jest akcentowanie tego faktu przy użyciu metaforyki przejętej ze Starego Testamentu.

Doskonałą ilustracją takiej metaforyki jest jeden z najpopularniejszych etiopskich poematów maryjnych Waddase Maryam („Pochwała Maryi”) ${ }^{40}$. W tekście Maryja przyrównana jest między innymi do: drabiny Jakubowej, krzewu gorejącego, skarbów nabytych przez Józefa ${ }^{41}$, bramy na wschodzie ${ }^{42}$, manny padającej na pustyni, laski Aarona i przybytku Świątyni. W kontekście ikonografii próby gorzkiej wody szczególnie ta ostatnia metafora wydaje się bardzo istotna.

W etiopskiej teologii istotnym konceptem jest zrównywanie Maryi z Syjonem, Arką Przymierza bądź Świątynią. Źródłem tego utożsamienia jest analogia pomiędzy Świątynią i Syjonem jako miejscem, gdzie Bóg nakazał złożyć Arkę a Maryją jako łonem, w którym wzrastał Chrystus. Analogia ta jest bardzo często przywoływana w etiopskiej literaturze. W jednym $\mathrm{z}$ hymnów jest to wyrażone zupełnie wprost:

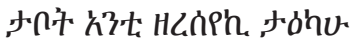

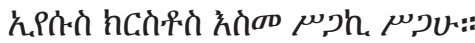

„Jesteś Arką, Ty którą [Pan] uczynił swoim pałacem

Jezus Chrystus - albowiem twoje ciało jest jego ciałem"43.

Można postawić hipotezę, że obecność motywu próby gorzkiej wody we wczesnych etiopskich ewangeliach wiąże się właśnie z tym specyficznie etiopskim postrzeganiem Maryi jako chrześcijańskiego odpowiednika starotestamentalnej Świątyni. Próba gorzkiej wody jest obok ofiarowania Maryi w Świątyni sztandarowym przykładem ikonografii łączącej Maryję ze Świątynią ${ }^{44}$. Hipoteza ta mogłaby zostać uprawdopodobniona przez badania, które ukazałyby historyczny rozwój etiopskiej mariologii, niestety nie zostały one dotychczas w zadowalającym stopniu przeprowadzone.

\section{BIBLIOGRAFIA}

Gomez de Silva C., The Temple in the iconography of Early Christian art, „Assaph. Studies in Art History" 1996, no. 2, s. 59-82.

${ }^{40}$ Przekładu polskiego z oryginału dokonał ks. prof. Stanisław Kur w: Teksty o Matce Bożej: kościoły przedchalcedońskie, wstęp, wybór, oprac., posł. Henryk Paprocki, Niepokalanów 1995, s. 37-47.

${ }^{41}$ Por. zapewne Rdz. 41-43.

42 Por. Ez. 10, 19.

43 A. Grohmann, Aethiopische Marienhymnen, Leipzig 1919, s. 376. Dalsze przykłady zob. tamże s. 19, 315, 337.

${ }^{44}$ Należy wszakże zauważyć, że Protoewangelia Jakuba nie podaje wprost, że próba miała miejsce w Świątyni. Jednak zarówno ikonografia wczesnochrześcijańska jak i zależna od niej ikonografia etiopska pokazuje, że tak właśnie przyjmowano. Por. C. Gomez de Silva, The Temple in the iconography of Early Christian art, Assaph. Studies in Art History 1996, no. 2, s. 70-72. 
Jäger O., Deininger-Englhart L., Some notes on illumination of manuscripts in Ethiopia, „Rassegna di Studi Etiopici" 1961, vol. 17, s. 45-60.

Jastrzębowska E., Bild und Wort : das Marienleben und die Kindheit Jesu in der christlichen Kunst vom 4. bis 8. Jh. und ihre apokryphen Quellen, Warszawa 1992.

Jensen R. M., The apocryphal Mary in early Christian art, w: The Oxford handbook of early Christian apocrypha, ed. by Andrew Gregory, Christopher M. Tuckett, Tobias Nicklas, Joseph Verheyden, Oxford 2016.

Kaplan S., Seeing is believing: the power of visual culture in the religious world of aşe Zär'a Ya'eqob of Ethiopia (1434-1468), „Journal of Religion in Africa” 2002, vol. 32, no. 4, s. 403-421.

Krawczuk M., Ewangeliarz abba Garima - najstarszy znany rękopis etiopski, „Iluminacje” 2013, nr 1, s. 21-23.

Krawczuk M., Kult maryjny w Etiopskim Kościele Ortodoksyjnym, „Afryka” 2015, T. 41, s. 67-80.

Krzyżanowska M., Contemporary scribes of eastern Tigray (Ethiopia), „Rocznik Orientalistyczny” 2015, vol. 68, no. 2, 2015, s. 73-101.

Langkammer H., Apokryfy Nowego Testamentu, Katowice 1989.

Lepage C., Reconstitution d'un cycle protobyzantin à partir des miniatures de deux manuscrits éthiopiens du XIVe siècle, „Cahiers Archéologiques” 35, 1987, s. 159-196.

Mercier J., Vierges d'Éthiopie, Montpellier 2004.

Nutzman M., Mary in the Protevangelium of James: a Jewish woman in the Temple?, „Greek, Roman, and Byzantine Studies"2013, vol. 53, no. 3, s. 551-578.

Pawłowska A., Selected motifs of Ethiopian iconography, „Series Byzantina” 2009, vol. 7, s. 83-92. Piovanelli P., Les aventures des apocryphes en Éthiopie, „Apocrypha” 1994, no 4, s. 197-224.

Waddäse Maryam qaddus Efrem yädärräsäw: käqädmo abbatočč siwärd siwarräd yämättaw nəbabunna targwame [Pochwała Maryi napisana przez świętego Efrema: tłumaczenie i objaśnienie przekazane w tradycji przez dawnych ojców], Addis Abäba 1983 [=1990/1991], s. 161.

Weitzmann K. (red.), Age of spirituality. Late Antique and Early Christian art, Third to Seventh Century, New York 1979, s. 450.

Witakowski W., The Miracles of Jesus: an Ethiopian apocryphal gospel, „Apocrypha” 1995, no 6, s. 279-298.

\section{Streszczenie}

Jedną z cech sztuki chrześcijańskiej Etiopii jest występowanie motywów ikonograficznych stosunkowo rzadkich w innych obszarach świata chrześcijańskiego. Wynika to między innymi z peryferyjnego położenia Etiopii i specyficznego kontekstu, w jakim rozwijała się tam sztuka religijna. Takim motywem jest między innymi próba gorzkiej wody, której według apokryficznej Protoewangelii Jakuba miała zostać poddana Maryja. Ta bardzo rzadka w sztuce wczesnochrześcijańskiej scena pojawia się ogółem w kilkunastu etiopskich iluminacjach, w większości pochodzących z rękopisów ewangelii. Etiopska ikonografia tej sceny wydaje się zależna od pierwowzorów wczesnochrześcijańskiej, zostały jednak do niej dodane pewne elementy, w szczególności symbole, które jednoznacznie łączą scenę ze Świątynią jerozolimską. Pozostaje to w zgodzie z typową tendencją etiopskiej mariologii to interpretowania postaci Maryi w kontekście Starego Testamentu. Być może to właśnie przesądziło o włączeniu próby gorzkiej wody do etiopskiej ikonografii maryjnej.

Słowa kluczowe: Maryja, Etiopia, ikonografia chrześcijańska, apokryfy, iluminacje rękopisów 


\section{NEW TESTAMENT APOCRYPHA AS A SOURCE OF INSPIRATION FOR CHRISTIAN ART: THE CASE OF THE ICONOGRAPHY OF THE ORDEAL BY BITTER WATER IN ETHIOPIAN ILLUMINATIONS}

\section{Sum mary}

One of the characteristics of Ethiopian Christian art is the presence of motifs which are relatively rare in other areas of the Christian world. An example of such a motif is the ordeal by bitter water which, according to the apocryphal Protoevangelium of James, Mary had to undergo. This scene, which is very rare in early Christian art, appears in ca. dozen Ethiopian illuminations, most of which come from Gospel manuscripts. The Ethiopian iconography of the scene appears to depend on the early Christian prototypes, however certain elements have been added, in particular some symbols connecting the scene to the Jerusalem Temple. This corresponds to the general trend in Ethiopian Mariology to interpret the figure of Mary through the Old Testament. This perhaps was the main reason to include the scene of the ordeal by bitter water to the Ethiopian Marian iconography.

Keywords: Virgin Mary, Ethiopia, Christian icnography, apocrypha, manuscript illuminations 